\title{
Effect of Interfacial Energetics on Charge Transfer from Lead Halide Perovskite to Organic Hole Conductors
}

\author{
Robert J. E. Westbrook, ${ }^{\dagger, \dagger}$ Dr. Irene Sanchez-Molina, ${ }^{\dagger}$ Dr. Jose Manuel Marin-Beloqui, ${ }^{\dagger}$
}

Dr. Hugo Bronstein, ${ }^{+\infty}$ and Dr. Saif A. Haque ${ }^{*}+{ }^{\dagger}$

${ }^{\dagger}$ Department of Chemistry and Centre for Plastic Electronics, Imperial College London, South Kensington Campus, London SW7 2AZ, U.K.

${ }^{\ddagger}$ Department of Chemistry, University College London, London, WC1H 0AJ, U.K.

\section{Supporting Information}

ABSTRACT: The control and optimization of interfacial charge transfer processes is crucial to the design of efficient perovskite solar cells. Herein, we measure the yield and kinetics of hole transfer across the methylammonium lead triiodide perovskitelpolymeric hole transport material heterojunction, as a function of the interfacial energy offset, $\Delta E$, between the highest occupied molecular orbital of the hole transport material and the valence band edge of the perovskite. A combination of steady-state and time-resolved photoluminescence, along with transient absorption spectroscopy, revealed that only a small driving energy $(\Delta E \sim 0.07 \mathrm{eV})$ is required to induce highly efficient hole transfer. The findings of this paper suggest that further improvements in the open-circuit voltage, and so the power conversion efficiency, of perovskite solar cells could be achieved by incorporating hole transport materials that provide an interfacial energy offset in the range $0<\Delta E<0.18 \mathrm{eV}$.

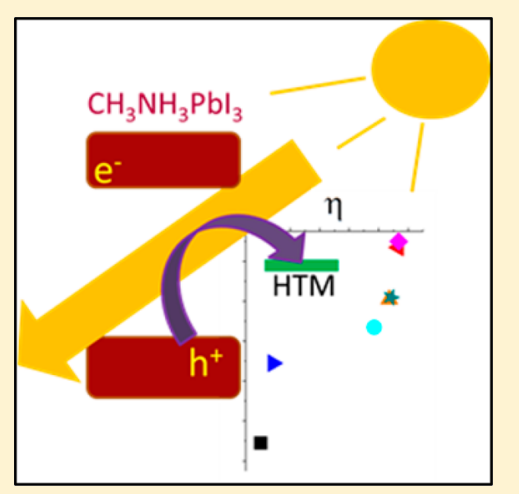

\section{INTRODUCTION}

The rapid emergence of perovskite solar cells (PSCs) over the past few years has created the potential to disrupt the established solar cell market due to their cheap cost, ${ }^{1}$ ease of processing, ${ }^{2}$ and aesthetic versatility. ${ }^{3,4}$ Perovskites have formula $\mathrm{ABX}_{3}$ where $\mathrm{A}\left(\mathrm{CH}_{3} \mathrm{NH}_{3}{ }^{+}, \mathrm{HC}\left(\mathrm{NH}_{2}\right)_{2}{ }^{+}, \mathrm{Cs}^{+}\right)$and $\mathrm{B}$ $\left(\mathrm{Pb}^{2+}, \mathrm{Sn}^{2+}\right)$ are cations and $\mathrm{X}\left(\mathrm{Br}^{-}, \mathrm{Cl}^{-}, \mathrm{I}^{-}\right)$is an anion. The methylammonium lead triiodide $\left(\mathrm{CH}_{3} \mathrm{NH}_{3} \mathrm{PbI}_{3}\right)$ perovskite was one of the first researched for solar cell applications, by the Miyasaka group in 2009. Since then, the power conversion efficiency (PCE) of PSCs has increased from $3.8 \%$ to the current record of $22.7 \% .^{6-11}$ The high efficiency of PSCs can be attributed to their unique properties such as highly mobile charge carriers with micrometer diffusion lengths, ${ }^{12,13}$ large extinction coefficient $\left(\sim 10^{5} \mathrm{~cm}^{-1}\right),{ }^{14}$ low exciton binding energy $(6 \mathrm{meV}),{ }^{15}$ and relatively large open-circuit voltage $\left(V_{\mathrm{OC}}\right)$ to band gap $\left(E_{\mathrm{g}}\right)$ ratio $(0.76) .{ }^{16}$ However, the further development and optimization of PSCs requires a better fundamental understanding of device function. Specifically, while many significant advances of PSC efficiency have come about due to hole transport material (HTM) selection, relatively little is known about charge separation at the perovskitelHTM interface.

It is well established that a significant energy offset, $\Delta E$, as shown in Figure 1, between the HTM HOMO level and the $\mathrm{CH}_{3} \mathrm{NH}_{3} \mathrm{PbI}_{3}$ valence band is required to drive hole extraction out of the photoactive layer of the solar cell. However, in contrast to the parallel fields of organic and dye-sensitized solar cells (OSCs and DSSCs), where the relationship between $\Delta E$ and the hole yield has been well-studied, ${ }^{17-19}$ research on this topic in PSCs has been limited.

In 2013, Marchioro et al. assigned time constants to the key charge transfer processes at the PSC interfaces, including the picosecond hole transfer to the current state-of-the-art HTM, spiro-OMeTAD. ${ }^{20}$ Importantly, this hole transfer process was found to be much faster than the subsequent recombination between the holes in the HTM and the electrons in the $\mathrm{CH}_{3} \mathrm{NH}_{3} \mathrm{PbI}_{3}$ conduction band. A later study by Brauer et al. demonstrated that hole transfer into polymeric HTMs is slower, typically on the order of nanoseconds. ${ }^{21}$ Both of these studies used transient absorption spectroscopy which can directly probe hole transfer at the $\mathrm{CH}_{3} \mathrm{NH}_{3} \mathrm{PbI}_{3} \mid \mathrm{HTM}$ interface. More recently, Ishida et al. studied the hole transfer process in PSC devices using the time-resolved microwave conductivity (TRMC) technique. ${ }^{22}$ However, while TRMC is an excellent probe of working devices, it is unable to distinguish between the different charge carriers and interfaces of the cell. There have so far been no studies addressing the effect of $\Delta E$ on hole yield at the $\mathrm{CH}_{3} \mathrm{NH}_{3} \mathrm{PbI}_{3} \mid \mathrm{HTM}$ heterojunction with techniques such as transient absorption spectroscopy.

Although the presence of a large $\Delta E$ at the perovskitelHTM interface should be beneficial for hole extraction, this parameter has important implications for the PCE of devices. Together with the short-circuit current $\left(J_{\mathrm{SC}}\right)$ and fill factor $(\mathrm{FF})$, the

Received: September 14, 2017

Revised: December 1, 2017

Published: January 5, 2018 


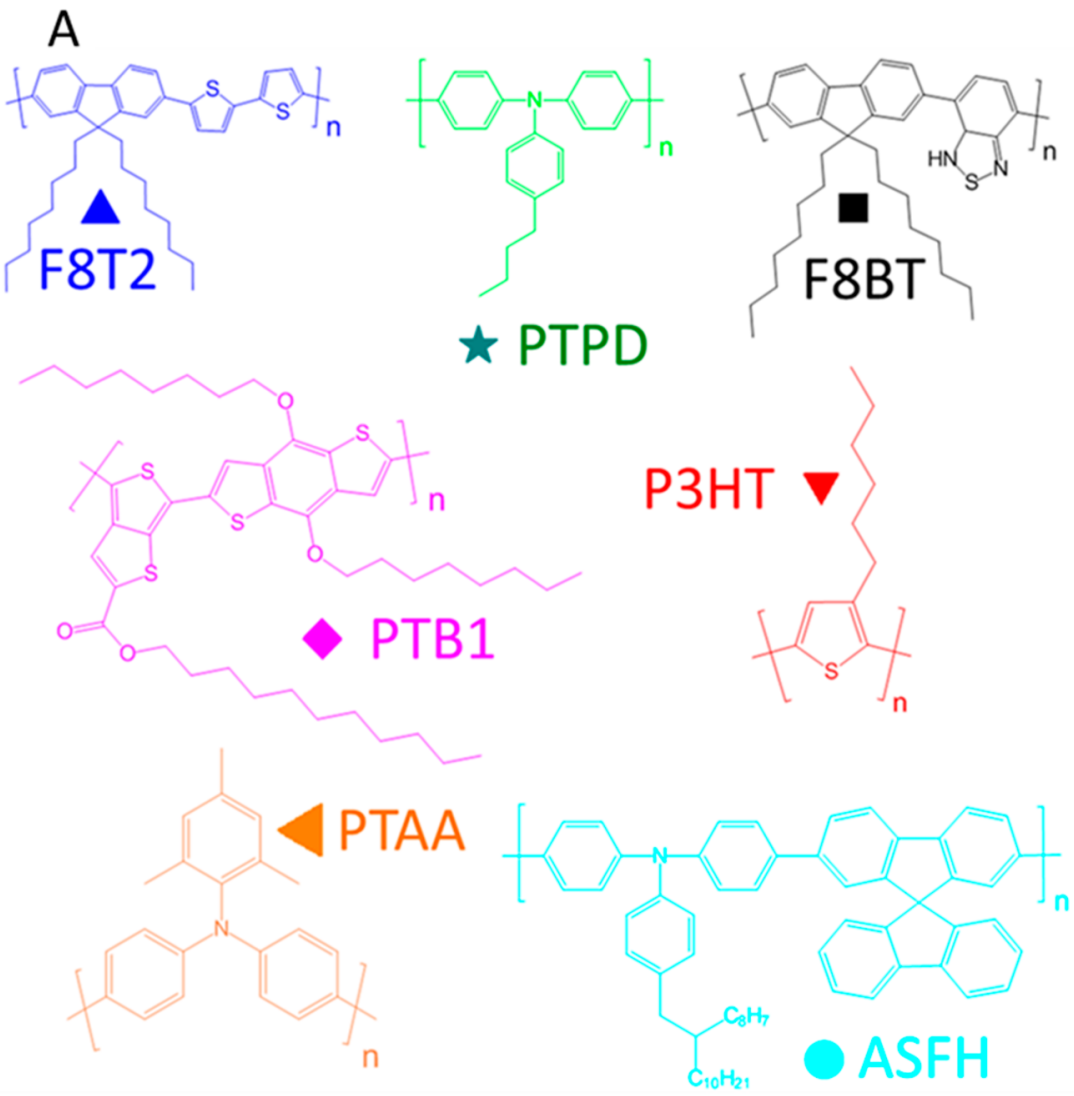

B

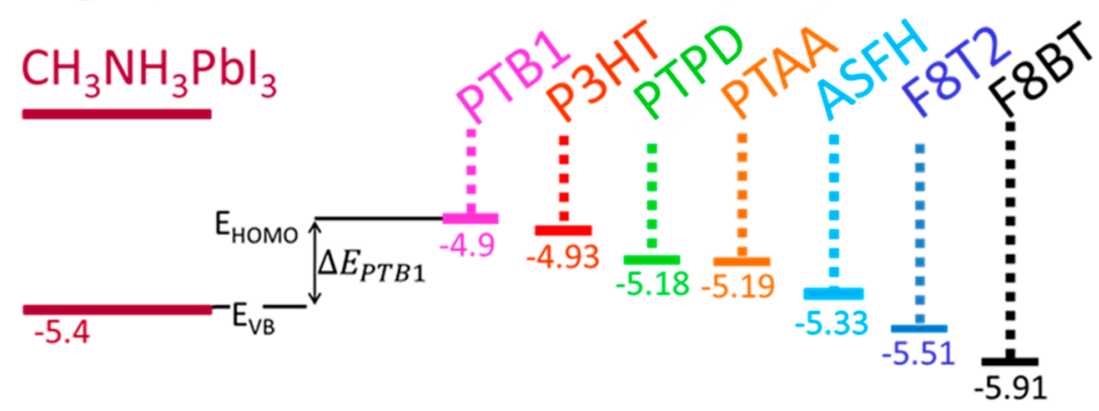

Figure 1. (a) Structures of all polymeric HTMs used in the present study. Note that each polymer is referenced by a unique symbol. (b) HOMO energies, $E_{\mathrm{HOMO}}$, of all HTMs shown relative to the $\mathrm{CH}_{3} \mathrm{NH}_{3} \mathrm{PbI}_{3}$ valence band energy, $E_{\mathrm{VB}}(-5.4 \mathrm{eV})$. The energetic driving force for hole transfer can be approximated as $\Delta E=E_{\mathrm{HOMO}}-E_{\mathrm{VB}}$ and has been indicated for the specific case of PTB1.

open-circuit voltage $\left(V_{\mathrm{OC}}\right)$ determines the PCE of a solar cell $\left(\mathrm{PCE}=V_{\mathrm{OC}} J_{\mathrm{SC}} \mathrm{FF} / P_{\text {in }}\right)$ when compared with the power $\left(P_{\text {in }}\right)$ of the incident light. Moreover, the $V_{\mathrm{OC}}$ is defined as the difference between the quasi-Fermi energies of electrons and holes in the solar cell under illumination, and thus the theoretical maximum of $V_{\mathrm{OC}}$ is related to the band gap, $E_{\mathrm{g}}$. When a HTM is introduced at the interface, the quasi-Fermi energy of holes at the heterojunction increases, and so the $V_{\mathrm{OC}}$ decreases. $^{23-26}$ Therefore, given the delicate balance between the driving energy for hole extraction, $\Delta E$, and the open-circuit voltage, $V_{\mathrm{OC}}$, a better understanding of charge separation in $\mathrm{CH}_{3} \mathrm{NH}_{3} \mathrm{PbI}_{3}$ heterojunctions could aid the future optimization of PSCs.

In this work, we probed the effect of $\Delta E$ on the yield and kinetics of charge separation at the $\mathrm{CH}_{3} \mathrm{NH}_{3} \mathrm{PbI}_{3} \mid \mathrm{HTM}$ heterojunction through steady-state and time-resolved photoluminescence (ss-PL and TRPL) along with microsecond transient absorption spectroscopy (TAS), allowing for an interface-specific probe of hole transfer and recombination. The resulting investigation revealed that relatively small values of $\Delta E$ are required to produce high hole yields in $\mathrm{CH}_{3} \mathrm{NH}_{3} \mathrm{PbI}_{3}$ PSCs, with subnanosecond hole transfer possible at $\Delta E \sim 0.07$ $\mathrm{eV}$. This has important implications for the design of PSCs, as we provide evidence that suggests the $V_{\mathrm{OC}}$ in $\mathrm{CH}_{3} \mathrm{NH}_{3} \mathrm{PbI}_{3}$ cells could be further increased toward the radiative limit of $1.33 \mathrm{~V},{ }^{27}$ possibly allowing for further gains in PCE.

\section{RESULTS AND DISCUSSION}

The following HTMs were used for the study (see Figure 1a for structures): poly $[(9,9-$ di-n-octylfluorenyl-2,7-diyl)-alt-(benzo$[2,1,3]$ thiadiazol-4,8-diyl) $]$ (F8BT), poly[[2,2'-bithiophene $]$ 5,5'-diyl(9,9-dioctyl-9H-fluorene-2,7-diyl)] (F8T2), poly-4',4" (4-(2-octyldodecyl)-N,N-diphenylaniline)-alt-2,7-(9,9'-spirobi[fluorene]) (ASFH), poly[bis (4-phenyl) $(2,4,6$ - 

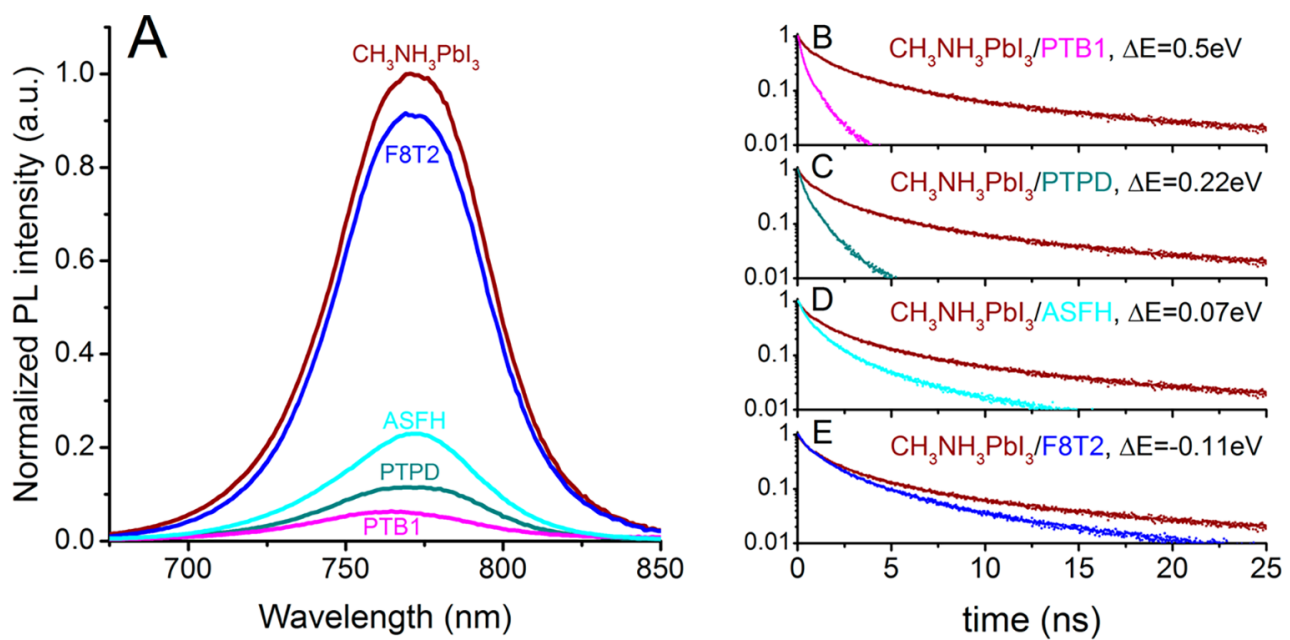

Figure 2. (a) ss-PL spectra for $\mathrm{CH}_{3} \mathrm{NH}_{3} \mathrm{PbI}_{3}$ compared with $\mathrm{CH}_{3} \mathrm{NH}_{3} \mathrm{PbI}_{3} \mid \mathrm{HTM}$ (HTM = F8T2, ASFH, PTPD, PTB1) samples excited at 510 nm. (b-e) PL decay kinetics for the same set of samples pumped at $635 \mathrm{~nm}$ and probed at $770 \mathrm{~nm}$.

trimethylphenyl)amine $]$ (PTAA), poly[ $N, N^{\prime}$-bis(4-butylphenyl)-N,N'-bisphenylbenzidine] (PTPD), poly(3-hexylthiophene2,5-diyl) (P3HT), or poly ((4,8-bis(octyloxy)benzo(1,2-b:4,5$\left.b^{\prime}\right)$ dithiophene-2,6-diyl $)$ (2-((dodecyloxy) carbonyl)thieno(3,4b)thiophenediyl) (PTB1).

Incorporating these HTMs in prototype PSCs gave rise to the $\mathrm{CH}_{3} \mathrm{NH}_{3} \mathrm{PbI}_{3} \mid \mathrm{HTM}$ interface energetics as shown in Figure 1b. The energies for the $\mathrm{CH}_{3} \mathrm{NH}_{3} \mathrm{PbI}_{3}$ valence band edge and HTM HOMO levels were obtained as described in the Supporting Information (see Figure S1 and Table S1).

By changing the HTM at the interface, $\Delta E$ could be modulated from $+0.5 \mathrm{eV}$ to $-0.51 \mathrm{eV}$. We note that samples were prepared via a one-step deposition of $\mathrm{CH}_{3} \mathrm{NH}_{3} \mathrm{PbI}_{3}$ on a mesoporous layer as reported elsewhere. ${ }^{28}$ Moreover, films were prepared in a nitrogen glovebox in order to avoid exposure to oxygen and light, the combination of which can rapidly degrade the $\mathrm{CH}_{3} \mathrm{NH}_{3} \mathrm{PbI}_{3}$ layer. ${ }^{29-32}$ Further details of sample processing can be found in the Supporting Information section 2.

We first studied the yield of hole transfer with steady-state photoluminescence (ss-PL). The resulting spectra of an illustrative set of $\mathrm{Al}_{2} \mathrm{O}_{3}\left|\mathrm{CH}_{3} \mathrm{NH}_{3} \mathrm{PbI}_{3}\right| \mathrm{HTM}$ ( $\mathrm{HTM}=\mathrm{F} 8 \mathrm{~T} 2$, ASFH, PTPD, PTB1) samples across the interfacial energy offset range $(\Delta E=-0.11,0.07,0.22,0.5 \mathrm{eV})$ are depicted in Figure $2 \mathrm{a}$ (see Figure $\mathrm{S} 2$ for all spectra). $\mathrm{CH}_{3} \mathrm{NH}_{3} \mathrm{PbI}_{3}$ exhibited an intense narrow emission at $770 \mathrm{~nm}$ due to the near-band-edge recombination between electrons and holes across the $1.6 \mathrm{eV}$ band gap. ${ }^{27}$ As shown in Figure $2 \mathrm{a}$ the $\mathrm{CH}_{3} \mathrm{NH}_{3} \mathrm{PbI}_{3}$ emission was quenched significantly in the presence of the HTMs, due to hole transfer from the $\mathrm{CH}_{3} \mathrm{NH}_{3} \mathrm{PbI}_{3}$ valence band into the HOMO level of the HTM. Moreover, the degree of quenching was found to correlate with $\Delta E$ at the interface, suggesting that HTMs with higher HOMO levels were more capable of hole extraction. Conversely, as shown in Figure S2, no quenching was observed when F8BT was used as a HTM due to the large hole transfer barrier of $0.51 \mathrm{eV}$ in this case. Interestingly, we find that the $\mathrm{CH}_{3} \mathrm{NH}_{3} \mathrm{PbI}_{3}$ photoactive layer is more emissive in the presence of F8BT relative to the pristine sample, possibly due to better passivation of surface defects in the former case. ${ }^{33}$

We next probed the real-time dynamics of hole transfer for the same set of samples using time-resolved photoluminescence (TRPL), with the results presented in Figure $2 \mathrm{~b}-\mathrm{e}$. We note that all steady-state and transient optical measurements were undertaken with the excitation light incident on the substrate side of the sample. Given the high extinction coefficient of $\mathrm{CH}_{3} \mathrm{NH}_{3} \mathrm{PbI}_{3}$, this ensured that there was minimal direct excitation of the HTM (see Figure S3). Supporting Information section 5 holds additional details of the characterization techniques mentioned in the main text.

The decay of the pristine $\mathrm{CH}_{3} \mathrm{NH}_{3} \mathrm{PbI}_{3}$ sample was fitted to a biexponential which accounted for a fast component due to emission from the surface, as well as a slow component due to emission from the bulk. ${ }^{24,34,35}$ The PL decays as well as fitting parameters for all $\mathrm{CH}_{3} \mathrm{NH}_{3} \mathrm{PbI}_{3} \mid \mathrm{HTM}$ samples can be found in Figure S4 and Table S3, respectively. As can be seen in Figure $2 \mathrm{~b}-\mathrm{e}$, the introduction of a HTM resulted in the acceleration of the $\mathrm{CH}_{3} \mathrm{NH}_{3} \mathrm{PbI}_{3} \mathrm{PL}$ decay due to hole transfer. Moreover, the decay was found to accelerate when $\Delta E$ was increased, with both the surface and bulk time constants decreasing. Therefore, to obtain a crude quantification of the extraction ability of a HTM, we define an estimate for the decay time, $\tau_{\mathrm{HT}}$, as the time taken for the PL signal to reach $50 \%$ of its initial value. We note that in the case of F8BT and F8T2 hole transfer appears to be slower than or on a similar timescale to the radiative recombination within the $\mathrm{CH}_{3} \mathrm{NH}_{3} \mathrm{PbI}_{3}$ layer. This means that no reliable kinetic information about hole extraction can be obtained for these HTMs with TRPL.

Figure 3 shows the effect of $\Delta E$ on $\tau_{\mathrm{HT}}$ as well as the quenching efficiency, $\eta$, which we define as

$$
\eta=\frac{\mathrm{PL}-\mathrm{PL}_{\mathrm{Q}}}{\mathrm{PL}}
$$

where $\mathrm{PL}$ and $\mathrm{PL}_{\mathrm{Q}}$ are the intensities of each of the $\mathrm{CH}_{3} \mathrm{NH}_{3} \mathrm{PbI}_{3} \mid \mathrm{HTM}$ samples before and after addition of the HTM. As the level of quenching is directly related to the concentration of holes removed from the perovskite valence band, $\eta$ is an indicator of relative hole yield. We note that $\eta$ is taken to be zero for $\mathrm{CH}_{3} \mathrm{NH}_{3} \mathrm{PbI}_{3} \mid \mathrm{F} 8 \mathrm{BT}$ as no quenching of the $\mathrm{CH}_{3} \mathrm{NH}_{3} \mathrm{PbI}_{3} \mathrm{PL}$ occurs in this case.

As expected, a higher yield of hole transfer is observed as $\Delta E$ is progressively increased. However, what is most striking here is the sharpness of this trend. For example, ASFH provides a driving energy of around $0.07 \mathrm{eV}$, but this $\mathrm{HTM}$ quenches $77 \%$ of the original $\mathrm{CH}_{3} \mathrm{NH}_{3} \mathrm{PbI}_{3} \mathrm{PL}$. A further increase of $\Delta E$ to 0.5 


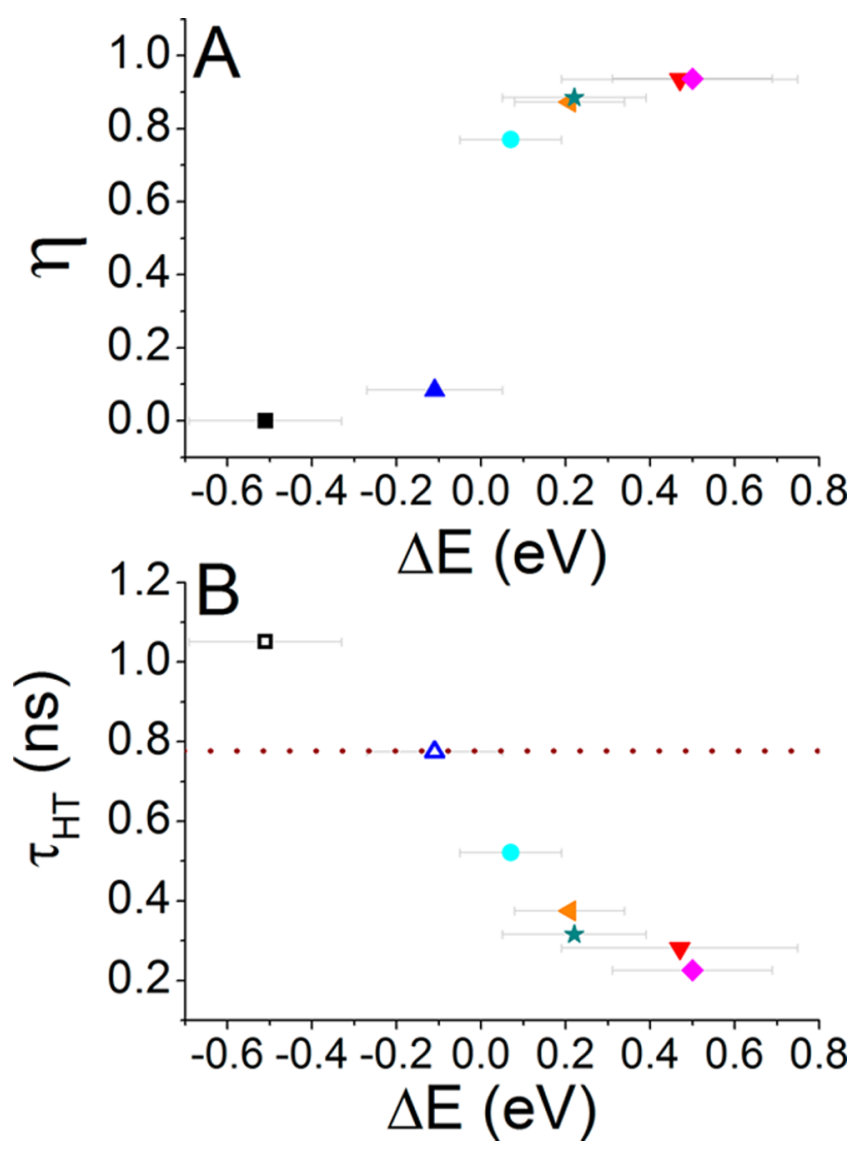

Figure 3. Effect of $\Delta E$ on (a) the quenching efficiency, $\eta$, and (b) the $\mathrm{PL}$ decay half-life, $\tau_{\mathrm{HT}}$, of the $\mathrm{CH}_{3} \mathrm{NH}_{3} \mathrm{PbI}_{3}$ IHTM samples. $\mathrm{CH}_{3} \mathrm{NH}_{3} \mathrm{PbI}_{3} \mid \mathrm{F} 8 \mathrm{BT}$ and $\mathrm{CH}_{3} \mathrm{NH}_{3} \mathrm{PbI}_{3} \mid \mathrm{F} 8 \mathrm{~T} 2$ are included in (b) (empty data points), but note that their decay lifetime is on similar or longer time scales to the unquenched $\mathrm{CH}_{3} \mathrm{NH}_{3} \mathrm{PbI}_{3}$ decay (brown dotted line).

$\mathrm{eV}$ in the case of PTB1 results in a relatively small gain of $17 \%$ in the value of $\eta$.

The relationship between the dynamics of hole transfer and $\Delta E$ is presented in Figure $3 \mathrm{~b}$. The PL decay half-life in the case of the pristine $\mathrm{CH}_{3} \mathrm{NH}_{3} \mathrm{PbI}_{3}$ film was found to be $777 \mathrm{ps}$, consistent with previous studies. ${ }^{36}$ However, as discussed above the lifetime was found to decrease in the case of the HTMcoated $\mathrm{CH}_{3} \mathrm{NH}_{3} \mathrm{PbI}_{3}$ samples. Upon raising the driving energy from $\Delta E \sim-0.51 \mathrm{eV}$ (F8BT) to $\Delta E \sim 0.07 \mathrm{eV}$ (ASFH), the PL decay became dominated by hole transfer, and a substantial decrease in $\tau_{\mathrm{HT}}$ to $521 \mathrm{ps}$ was observed. This suggests that hole transfer occurs on a subnanosecond time scale at a driving energy of just $0.07 \mathrm{eV}$. We note that all observed values for $\tau_{\mathrm{HT}}$ were found to be much larger than the instrumental response half-life of 100 ps (see "prompt" in Figure S4), allowing for the accurate assignation of these PL decay dynamics.

Remarkably, despite a hole transfer barrier of $0.11 \mathrm{eV}$, the polymer F8T2 still produces a $\eta$ of $8.4 \%$. The interfacial barrier in this case is too large for hole transfer to occur via thermal excitation alone $\left(k_{\mathrm{B}} T=0.026 \mathrm{eV}\right.$ at $\left.298 \mathrm{~K}\right)$, and so another factor must be influencing the hole transfer process in this system. At present, we can only speculate on the origin of this observation. The high level of structural disorder in polymeric materials typically results in a distribution of energies around the quoted HOMO level. ${ }^{18,37}$ Consequently, even though the $\mathrm{HOMO}$ energy seems to be situated below the $\mathrm{CH}_{3} \mathrm{NH}_{3} \mathrm{PbI}_{3}$ valence band, the energetic disorder produces tail states that lie at a favorable energy, and thus hole transfer can still be spontaneous. Such energetic disorder has been found previously to effect hole transfer in DSSCs. ${ }^{18,38}$

Hole injection was further investigated by performing transient absorption spectroscopy (TAS). Experimental details of our TAS setup are given in Supporting Information section 5 and are published elsewhere. ${ }^{29,39,40}$ Figure 4a presents the TAS spectra for $\mathrm{TiO}_{2}\left|\mathrm{CH}_{3} \mathrm{NH}_{3} \mathrm{PbI}_{3}\right| \mathrm{HTM}(\mathrm{HTM}=\mathrm{F} 8 \mathrm{~T} 2, \mathrm{ASFH}$, PTPD, PTB1) samples taken $3 \mu$ s after excitation at $510 \mathrm{~nm}$. As can be seen, a spectrum with broad features in the near-infrared was obtained after excitation of the $\mathrm{CH}_{3} \mathrm{NH}_{3} \mathrm{PbI}_{3}$ photoactive layer, in the presence of these HTMs. Given that (i) no transient signal is observed for pristine $\mathrm{TiO}_{2} \mid \mathrm{CH}_{3} \mathrm{NH}_{3} \mathrm{PbI}_{3}$ samples without a HTM; (ii) the $\mathrm{CH}_{3} \mathrm{NH}_{3} \mathrm{PbI}_{3} \mid \mathrm{ASFH}$, $\mathrm{CH}_{3} \mathrm{NH}_{3} \mathrm{PbI}_{3} \mid \mathrm{F} 8 \mathrm{~T} 2$, and $\mathrm{CH}_{3} \mathrm{NH}_{3} \mathrm{PbI}_{3} \mid \mathrm{PTPD}$ spectra closely match the absorption profile of chemically oxidized ASFH, F8T2, and PTPD (Figure S5a-c); and (iii) the $\mathrm{CH}_{3} \mathrm{NH}_{3} \mathrm{PbI}_{3} \mathrm{I}$ PTB1 spectrum is consistent with a spectrum previously published for $\mathrm{PTB} 1{ }^{41}$ the transient spectra can be assigned to the formation of hole polarons on the HTM due to extraction from the $\mathrm{CH}_{3} \mathrm{NH}_{3} \mathrm{PbI}_{3}$ valence band. Moreover, these observations provide direct evidence that the quenching of the $\mathrm{CH}_{3} \mathrm{NH}_{3} \mathrm{PbI}_{3} \mathrm{PL}$ presented in Figures 2 and 3 is indeed due to hole transfer to the HTM.

The population of holes in the different $\mathrm{CH}_{3} \mathrm{NH}_{3} \mathrm{PbI}_{3} \mid \mathrm{HTM}$ combinations was monitored by probing the maximum of the transient absorption band as a function of time after excitation. The resulting traces are shown in Figure $4 \mathrm{~b}$ for F8T2, ASFH, PTPD, and PTB1 (see Figure S6 for all HTMs). As holes in the HTM recombine with the electrons of the $\mathrm{CH}_{3} \mathrm{NH}_{3} \mathrm{PbI}_{3}$ conduction band, the signal decays nonexponentially and can be fitted with a stretched exponential function: $\Delta \mathrm{OD} \propto \exp \left[-\left(\frac{t}{\tau}\right)^{\alpha}\right] \cdot{ }^{18}$ This type of decay is consistent with recombination in systems that contain a significant amount of disorder. $^{18,20,42}$ In this case, the stretched exponential could signify the energetic disorder of the HTM as well as recombination over a broad range of distances. The decay lifetime, $\tau_{\text {rec }}$ can be approximated as the time taken for the signal to drop to $50 \%$ of its original value. ${ }^{18,39}$

Having a large ratio between the time constants for extraction and recombination is important for sustained charge separation in a solar cell. Indeed, Marchioro et al. found that this ratio was on the order of $10^{6}$ in the case of state-of-the-art HTM spiro-OMeTAD. ${ }^{20}$ Table 1 shows that similar ratios are obtained with polymeric HTMs, as $\tau_{\text {rec }}$ is at least 200000 times slower than $\tau_{\mathrm{HT}}$ in all cases where the HTM is energetically capable of hole extraction.

In Figure $4 c$, we plot the maximum of the transient absorption trace, $\Delta \mathrm{OD}_{\max }$ against $\Delta E . \Delta \mathrm{OD}$ is related to the concentration of photogenerated transient species and so the yield of hole transfer. Therefore, these data suggest that hole injection increases with $\Delta E$ and supports the general trend found in the PL study. However, we stress that in order to obtain an absolute yield from TAS the signal must be corrected for the extinction coefficient of the oxidized polymer in accordance with the Beer-Lambert law.

A key feature of PSCs that has been at the heart of their unprecedented rise in PCE over recent years is their high $V_{\mathrm{OC}} /$ $E_{\mathrm{g}}$ ratio of $0.76 .^{16}$ This compares favorably to the same parameter in other solution-processed photovoltaic technologies such as OSCs, in which $V_{\mathrm{OC}} / E_{\mathrm{g}}$ is rarely higher than 0.55 . $^{43}$ 


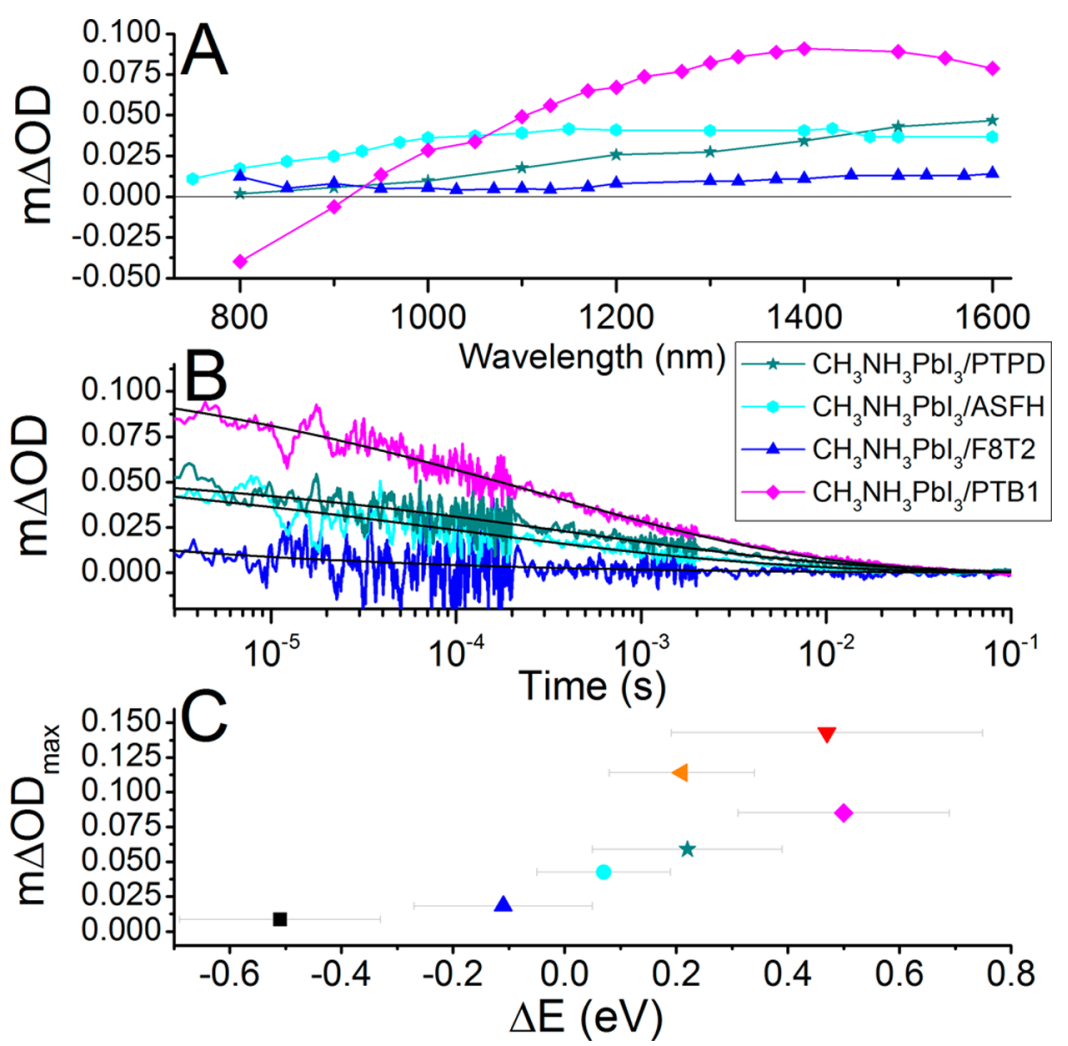

Figure 4. (a) TAS spectra in the NIR of hole polarons on F8T2, ASFH, PTPD, and PTB1 obtained by exciting $\mathrm{CH}_{3} \mathrm{NH}_{3} \mathrm{PbI}_{3} \mid \mathrm{HTM}$ samples at 510 $\mathrm{nm}$. (b) TAS decay kinetics for the same samples probed at the maximum of their TAS spectrum. (c) Maximum of TAS trace, taken at $3 \mu$ s for all HTMs probed in this study.

Table 1. Summary of the Key Results Found for the $\mathrm{CH}_{3} \mathrm{NH}_{3} \mathrm{PbI}_{3} \mid \mathrm{HTM}$ Samples Investigated

\begin{tabular}{lcllllc} 
HTM & $\begin{array}{c}\Delta E \\
(\mathrm{eV})\end{array}$ & \multicolumn{1}{c}{$\eta$} & $m \Delta \mathrm{OD}_{\max }$ & $\tau_{\mathrm{HT}}(\mathrm{ps})$ & $\tau_{\text {rec }}(\mathrm{ms})$ & $\begin{array}{c}\tau_{\text {rec }} / \tau_{\mathrm{HT}} \\
\left(\times 10^{6}\right)\end{array}$ \\
F8BT & -0.51 & 0 & 0.0071 & - & - & - \\
F8T2 & -0.11 & 0.084 & 0.0141 & - & - & - \\
ASFH & 0.07 & 0.77 & 0.0419 & 521 & 0.16 & 0.3 \\
PTAA & 0.21 & 0.873 & 0.109 & 375 & 0.0792 & 0.2 \\
PTPD & 0.22 & 0.885 & 0.0468 & 316 & 0.36 & 1.1 \\
P3HT & 0.47 & 0.935 & 0.139 & 282 & 1.21 & 4.3 \\
PTB1 & 0.5 & 0.937 & 0.0907 & 226 & 0.453 & 2 \\
\hline
\end{tabular}

In donor-acceptor OSC devices, exciton binding energies can be as high as $0.5 \mathrm{eV},{ }^{44}$ meaning that in order to produce an electron and hole by harvesting an exciton a large energy offset must be installed at the donor-acceptor interface. This has the negative effect of decreasing the quasi-Fermi level splitting and so the $V_{\mathrm{OC}}$. It has been shown here that this is not the case for $\mathrm{CH}_{3} \mathrm{NH}_{3} \mathrm{PbI}_{3}$ as remarkably high hole yields can be achieved at low $\Delta E$. This is most probably because the binding energy of excitons within $\mathrm{CH}_{3} \mathrm{NH}_{3} \mathrm{PbI}_{3}$ is around $6 \mathrm{meV}$, ${ }^{15}$ and so at room temperature they are easily thermalized into free electrons and holes that can be extracted with ease. Therefore, the current observations help rationalize the favorable $V_{\mathrm{OC}} / E_{\mathrm{g}}$ ratio in PSCs compared to OSCs as less voltage loss is necessary for hole extraction in the former case.

The present study has also shown evidence for possible future gains in the $V_{\mathrm{OC}}$ of PSCs. As found by the Seok group, the $V_{\mathrm{OC}}$ is maximized when the $\mathrm{CH}_{3} \mathrm{NH}_{3} \mathrm{PbI}_{3} \mid \mathrm{HTM}$ energy offset, $\Delta E$, is at a minimum. ${ }^{23}$ We have shown here that highly efficient hole extraction at the $\mathrm{CH}_{3} \mathrm{NH}_{3} \mathrm{PbI}_{3}$ IHTM interface is possible at $\Delta E \sim 0.07 \mathrm{eV}$. Moreover, at this value of $\Delta E$, hole extraction is on the order of 100,000 times faster than the subsequent electron-hole recombination across the heterojunction. With this in mind, the $V_{\mathrm{OC}}$ of future PSCs could be optimized by incorporating HTMs with $\Delta E$ in the range $0<$ $\Delta E<0.18 \mathrm{eV}$, without dramatic losses in the value of $J_{\mathrm{SC}}$. This goes some way to explaining the success of HTMs with deeplying HOMO levels such as PTAA, ${ }^{45} \mathrm{TFB}^{46}{ }^{46} \mathrm{KR}_{131},{ }^{47}$ and TPA-CN ${ }^{48}$ as these materials can extract a significant amount of charge while minimizing the voltage loss in the cell.

\section{CONCLUSIONS}

In summary, we have employed transient and steady-state optical spectroscopy to probe hole extraction at the $\mathrm{CH}_{3} \mathrm{NH}_{3} \mathrm{PbI}_{3} \mathrm{IHTM}$ interface. $\mathrm{PL}$ spectroscopy illuminated the acute trend between the hole yield and the interfacial energy offset, $\Delta E$, with $\eta=77 \%$ and hole transfer on the subnanosecond scale at $\Delta E \sim 0.07 \mathrm{eV}$. Further increases in $\Delta E$ beyond this value resulted in relatively small improvements in extraction. In addition, hole transfer has been observed through energetic barriers of around $0.11 \mathrm{eV}$, which has been tentatively attributed to energetic disorder at the $\mathrm{CH}_{3} \mathrm{NH}_{3} \mathrm{PbI}_{3} \mid \mathrm{HTM}$ heterojunction. The findings of the $\mathrm{PL}$ study have been supported by TAS measurements, which proved the full transfer of holes from the $\mathrm{CH}_{3} \mathrm{NH}_{3} \mathrm{PbI}_{3}$ valence band to the HTM. Moreover, TAS measurements demonstrated that the recombination of holes in the HTM with electrons in the $\mathrm{CH}_{3} \mathrm{NH}_{3} \mathrm{PbI}_{3}$ conduction band typically occurs at least 200000 times slower than the initial hole transfer. The implications of these findings for the $V_{\mathrm{OC}}$ of PSCs have been highlighted, and 
we suggest that further gains could be made by using HTMs with $0<\Delta E<0.18 \mathrm{eV}$ in future PSC designs.

\section{ASSOCIATED CONTENT}

\section{S Supporting Information}

The Supporting Information is available free of charge on the ACS Publications website at DOI: 10.1021/acs.jpcc.7b09178.

Valence Band Edge and HOMO energies for $\mathrm{CH}_{3} \mathrm{NH}_{3} \mathrm{PbI}_{3}$ and HTMs; Experimental methods; Complementary steady-state photoluminescence data; $\mathrm{CH}_{3} \mathrm{NH}_{3} \mathrm{PbI}_{3}$ absorption; Characterization techniques; Complementary Time-resolved photoluminescence data; Chemical oxidation of HTMs and Supporting TAS data (PDF)

\section{AUTHOR INFORMATION}

\section{Corresponding Author}

*to SAH (s.a.haque@imperial.ac.uk).

ORCID $\odot$

Dr. Hugo Bronstein: 0000-0003-0293-8775

Dr. Saif A. Haque: 0000-0001-5483-3321

Notes

The authors declare no competing financial interest.

\section{ACKNOWLEDGMENTS}

S. A. H. acknowledges financial support from the EPRSC via $\mathrm{EP} / \mathrm{M} 023532 / 1, \mathrm{EP} / \mathrm{K} 010298 / 1$, and EP/K030671/1 grants. R. W. was supported by the EPSRC Centre for Doctoral Training in Advanced Characterisation of Materials (EP/ L015277/1).

\section{REFERENCES}

(1) Cai, M.; Wu, Y.; Chen, H.; Yang, X.; Qiang, Y.; Han, L. CostPerformance Analysis of Perovskite Solar Modules. Adv. Sci. 2017, 4, 1600269.

(2) You, J.; Hong, Z.; Yang, Y. M.; Chen, Q.; Cai, M.; Song, T.; Chen, C.; et al. Perovskite Solar Cells with High Efficiency and Flexibility. ACS Nano 2014, 8, 1674-1680.

(3) Zhang, W.; Eperon, G. E.; Snaith, H. J. Metal Halide Perovskites for Energy Applications. Nat. Energy 2016, 1, 16048.

(4) Noh, J. H.; Im, S. H.; Heo, J. H.; Mandal, T. N.; Seok, S. Il Chemical Management for Colorful, Efficient, and Stable InorganicOrganic Hybrid Nanostructured Solar Cells. Nano Lett. 2013, 13, 1764-1769.

(5) Kojima, A.; Teshima, K.; Shirai, Y.; Miyasaka, T. Organometal Halide Perovskites as Visible- Light Sensitizers for Photovoltaic Cells. J. Am. Chem. Soc. 2009, 131, 6050-6051.

(6) Lee, M. M.; Teuscher, J.; Miyasaka, T.; Murakami, T. N.; Snaith, H. J. Efficient Hybrid Solar Cells Based on Meso-Superstructured Organometal Halide Perovskites. Science 2012, 338, 643-647.

(7) Heo, J. H.; Im, S. H.; Noh, J. H.; Mandal, T. N.; Lim, C.-S.; Chang, J. A.; Lee, Y. H.; Kim, H.; Sarkar, A.; NazeeruddinMd, K.; et al. Efficient Inorganic-Organic Hybrid Heterojunction Solar Cells Containing Perovskite Compound and Polymeric Hole Conductors. Nat. Photonics 2013, 7, 486-491.

(8) Tao, C.; Neutzner, S.; Colella, L.; Marras, S.; Ram, A.; Kandada, S.; Gandini, M.; De Bastiani, M.; Pace, G.; Manna, L.; et al. 17.6\% Stabilized Efficiency in Low-Temperature Processed Planar Perovskite Solar Cells. Energy Environ. Sci. 2015, 8, 2365-2370.

(9) Liu, M.; Johnston, M. B.; Snaith, H. J. Efficient Planar Heterojunction Perovskite Solar Cells by Vapour Deposition. Nature 2013, 501, 395-398.

(10) Burschka, J.; Pellet, N.; Moon, S.-J.; Humphry-Baker, R.; Gao, P.; Nazeeruddin, M. K.; Grätzel, M. Sequential Deposition as a Route to High-Performance Perovskite-Sensitized Solar Cells. Nature 2013, 499, 316-320.

(11) National Renewable Energy Labs (NREL). Best Research Cell Efficiencies https://www.nrel.gov/pv/assets/images/efficiency-chart. png (accessed 27 Nov, 2017).

(12) Stranks, S. D.; Stranks, S. D.; Eperon, G. E.; Grancini, G.; Menelaou, C.; Alcocer, M. J. P.; Leijtens, T.; Herz, L. M.; Petrozza, A.; Snaith, H. J. Electron-Hole Diffusion Lengths Exceeding 1 Micrometer in an Organometal Trihalide Perovskite Absorber. Science 2013, 342, $341-344$.

(13) Shi, D.; Adinolfi, V.; Comin, R.; Yuan, M.; Alarousu, E.; Buin, A.; Chen, Y.; Hoogland, S.; Rothenberger, A.; Katsiev, K.; et al. Solar Cells. Low Trap-State Density and Long Carrier Diffusion in Organolead Trihalide Perovskite Single Crystals. Science 2015, 347, 519-522.

(14) Sun, S.; Salim, T.; Mathews, N.; Duchamp, M.; Boothroyd, C.; Xing, G.; Sum, T. C.; Lam, Y. M. The Origin of High Efficiency in Low-Temperature Solution-Processable Bilayer Organometal Halide Hybrid Solar Cells. Energy Environ. Sci. 2014, 7, 399-407.

(15) Miyata, A.; Mitioglu, A.; Plochocka, P.; Portugall, O.; Wang, J. T.; Stranks, S. D.; Snaith, H. J.; Nicholas, R. J. Direct Measurement of the Exciton Binding Energy and Effective Masses for Charge Carriers in Organic-Inorganic Tri-Halide Perovskites. Nat. Phys. 2015, 11, 582-587.

(16) Saliba, M.; Matsui, T.; Domanski, K.; Seo, J.; Ummadisingu, A.; Zakeeruddin, M.; Tress, W. R.; Abate, A.; Hagfeldt, A.; Grätzel, M. Incorporation of Rubidium Cations into Perovskite Solar Cells Improves Photovoltaic Performance. Science 2016, 354, 206.

(17) Dimitrov, S. D.; Bakulin, A. A.; Nielsen, C. B.; Schroeder, B. C.; Du, J.; Bronstein, H.; McCulloch, I.; Friend, R. H.; Durrant, J. R. On the Energetic Dependence of Charge Separation in Low-Band-Gap Polymer/fullerene Blends. J. Am. Chem. Soc. 2012, 134, 18189-18192.

(18) Haque, S. A.; Park, T.; Holmes, A. B.; Durrant, J. R. Transient Optical Studies of Interfacial Energetic Disorder at Nanostructured Dye-Sensitised Inorganic/Organic Semiconductor Heterojunctions. ChemPhysChem 2003, 4, 89-93.

(19) Weisspfennig, C. T.; Lee, M. M.; Teuscher, J.; Docampo, P.; Stranks, S. D.; Joyce, H. J.; Bergmann, H.; Bruder, I.; Kondratuk, D. V.; Johnston, M. B.; et al. Optimizing the Energy Offset between Dye and Hole-Transporting Material in Solid-State Dye-Sensitized Solar Cells. J. Phys. Chem. C 2013, 117, 19850-19858.

(20) Marchioro, A.; Teuscher, J.; Friedrich, D.; Kunst, M.; van de Krol, R.; Moehl, T.; Gratzel, M.; Moser, J.-E. Unravelling the Mechanism of Photoinduced Charge Transfer Processes in Lead Iodide Perovskite Solar Cells. Nat. Photonics 2014, 8, 250-255.

(21) Brauer, J. C.; Lee, Y. H.; Nazeeruddin, M. K.; Banerji, N. Charge Transfer Dynamics from Organometal Halide Perovskite to Polymeric Hole Transport Materials in Hybrid Solar Cells. J. Phys. Chem. Lett. 2015, 6, 3675-3681.

(22) Ishida, N.; Wakamiya, A.; Saeki, A. Quantifying Hole Transfer Yield from Perovskite to Polymer Layer: Statistical Correlation of Solar Cell Outputs with Kinetic and Energetic Properties. ACS Photonics 2016, 3, 1678.

(23) Ryu, S.; Noh, J. H.; Jeon, N. J.; Kim, Y. C.; Yang, W. S.; Seo, J.; Seok, S. Il. Voltage Output of Efficient Perovskite Solar Cells with High Open-Circuit Voltage and Fill Factor. Energy Environ. Sci. 2014, 7, 2614-2618.

(24) Arora, N.; Orlandi, S.; Dar, M. I.; Aghazada, S.; Jacopin, G.; Cavazzini, M.; Mosconi, E.; Gratia, P.; De Angelis, F.; Pozzi, G.; et al. High Open-Circuit Voltage: Fabrication of Formamidinium Lead Bromide Perovskite Solar Cells Using Fluorene-Dithiophene Derivatives as Hole-Transporting Materials. ACS Energy Lett. 2016, $1,107-112$

(25) Yan, W.; Li, Y.; Ye, S.; Li, Y.; Rao, H.; Liu, Z.; Wang, S.; Bian, Z.; Huang, C. Increasing Open Circuit Voltage by Adjusting Work Function of Hole-Transporting Materials in Perovskite Solar Cells. Nano Res. 2016, 9, 1600-1608.

(26) Polander, L. E.; Pahner, P.; Schwarze, M.; Saalfrank, M.; Koerner, C.; Leo, K.; Polander, L. E.; Pahner, P.; Schwarze, M.; 
Saalfrank, M.; et al. Hole-Transport Material Variation in Fully Vacuum Deposited Perovskite Solar Cells. APL Mater. 2014, 2, 81503.

(27) Tvingstedt, K.; Malinkiewicz, O.; Baumann, A.; Deibel, C.; Snaith, H. J.; Dyakonov, V.; Bolink, H. J. Radiative Efficiency of Lead Iodide Based Perovskite Solar Cells. Sci. Rep. 2015, 4, 6071.

(28) Jeon, N. J.; Noh, J. H.; Kim, Y. C.; Yang, W. S.; Ryu, S.; Seok, S. Il. Solvent Engineering for High-Performance Inorganic-Organic Hybrid Perovskite Solar Cells. Nat. Mater. 2014, 13, 897-903.

(29) O'Mahony, F. T. F.; Lee, Y. H.; Jellet, C.; Dimitrov, S.; Bryant, D. T. J.; Durrant, J. R.; Regan, B. C. O.; Graetzel, M.; Nazeeruddin, M. K.; Haque, S. A. Improved Environmental Stability of Organic Lead Trihalide Perovskite-Based Photoactive-Layers in the Presence of Mesoporous TiO2. J. Mater. Chem. A 2015, 3, 7219-7223.

(30) Aristidou, N.; Sanchez-Molina, I.; Chotchuangchutchaval, T.; Brown, M.; Martinez, L.; Rath, T.; Haque, S. A. The Role of Oxygen in the Degradation of Methylammonium Lead Trihalide Perovskite Photoactive Layers. Angew. Chem., Int. Ed. 2015, 54, 8208-8212.

(31) Bryant, D.; Aristidou, N.; Pont, S.; Sanchez-molina, I.; Chotchunangatchaval, T.; Wheeler, S.; Durrant, R.; Haque, S. A. Light and Oxygen Induced Degradation Limits the Operational Stability of Methylammonium Lead Triiodide Perovskite Solar Cells. Energy Environ. Sci. 2016, 9, 1655-1660.

(32) Aristidou, N.; Eames, C.; Sanchez-molina, I.; Bu, X.; Kosco, J.; Islam, M. S.; Haque, S. A. Fast Oxygen Diffusion and Iodide Defects Mediate Oxygen-Induced Degradation of Perovskite Solar Cells. Nat. Commun. 2017, 8, 15218.

(33) Noel, N. K.; Abate, A.; Stranks, S. D.; Parrott, E. S.; Burlakov, V. M.; Goriely, A.; Snaith, H. J.; Al, N. E. T. Enhanced Photoluminescence and Solar Cell Performance via Lewis Base Passivation of Organic À Inorganic Lead Halide Perovskites. ACS Nano 2014, 8, 9815-9821.

(34) Shi, D.; Adinolfi, V.; Comin, R.; Yuan, M.; Alarousu, E.; Buin, A.; Chen, Y.; Hoogland, S.; Rothenberger, A.; Katsiev, K.; et al. Low Trap-State Density and Long Carrier Diffusion in Organolead Trihalide Perovskite Single Crystals. Science 2015, 347, 519-522.

(35) De Bastiani, M.; D’Innocenzo, V.; Stranks, S. D.; Snaith, H. J.; Petrozza, A. Role of the Crystallization Substrate on the Photoluminescence Properties of Organolead Mixed Halides Perovskites. APL Mater. 2014, 2, 081509.

(36) Wu, B.; Nguyen, H. T.; Ku, Z.; Han, G.; Giovanni, D.; et al. Discerning the Surface and Bulk Recombination Kinetics of Organic Inorganic Halide Perovskite Single Crystals. Adv. Energy Mater. 2016, 6,1600551 .

(37) Noriega, R.; Rivnay, J.; Vandewal, K.; Koch, F. P. V.; Stingelin, N.; Smith, P.; Toney, M. F.; Salleo, A. A General Relationship between Disorder, Aggregation and Charge Transport in Conjugated Polymers. Nat. Mater. 2013, 12, 1038-1044.

(38) Bisquert, J.; Palomares, E.; Quinones, C. A. Effect of Energy Disorder in Interfacial Kinetics of Dye-Sensitized Solar Cells with Organic Hole Transport Material. J. Phys. Chem. B 2006, 110, 1940619411.

(39) Guijarro, N.; Lutz, T.; Lana-Villarreal, T.; O’Mahony, F.; Gomez, R.; Haque, S. A. Toward Antimony Selenide Sensitized Solar Cells: Efficient Charge Photogeneration at Spiro-OMeTAD/Sb2Se3/ Metal Oxide Heterojunctions. J. Phys. Chem. Lett. 2012, 3, 1351.

(40) Reynolds, L. X.; Lutz, T.; Dowland, S.; Maclachlan, A.; King, S.; Haque, S. A. Charge Photogeneration in Hybrid Solar Cells: A Comparison between Quantum Dots and in Situ Grown CdS. Nanoscale 2012, 4, 1561-1564.

(41) Huo, M.; Hu, R.; Xing, Y.; Liu, Y.; Ai, X.; et al. Impacts of Side Chain and Excess Energy on the Charge Photogeneration Dynamics of Low-Bandgap Copolymer-Fullerene Blends. J. Chem. Phys. 2014, 140, 084903-084915.

(42) Nelson, J.; Haque, S.; Klug, D.; Durrant, J. Trap-Limited Recombination in Dye-Sensitized Nanocrystalline Metal Oxide Electrodes. Phys. Rev. B: Condens. Matter Mater. Phys. 2001, 63, 205321.
(43) Shao, Y.; Yuan, Y.; Huang, J. Correlation of Energy Disorder and Open-Circuit Voltage in Hybrid Perovskite Solar Cells. Nat. Energy 2016, 1, 15001.

(44) Servaites, J. D.; Ratner, M. a.; Marks, T. J. Organic Solar Cells: A New Look at Traditional Models. Energy Environ. Sci. 2011, 4, 44104422.

(45) Yang, W. S.; Noh, J. H.; Jeon, N. J.; Kim, Y. C.; Ryu, S.; Seo, J.; Seok, S. I. High-Performance Photovoltaic Perovskite Layers Fabricated through Intramolecular Exchange. Science 2015, 348, 1234.

(46) Zhu, Z.; Bai, Y.; Lee, H. K. H.; Mu, C.; Zhang, T.; Zhang, L.; Wang, J.; Yan, H.; So, S. K.; Yang, S. Polyfluorene Derivatives Are High-Performance Organic Hole-Transporting Materials for Inorganic-Organic Hybrid Perovskite Solar Cells. Adv. Funct. Mater. 2014, 24, 7357-7365.

(47) Rakstys, K.; Abate, A.; Dar, M. I.; Gao, P.; Jankauskas, V.; Kamarauskas, E.; Kazim, S.; Ahmad, S.; Nazeeruddin, M. K. Triazatruxene-Based Hole Transporting Materials for Highly Efficient Perovskite Solar Cells. J. Am. Chem. Soc. 2015, 137, 16172.

(48) Grancini, G.; Paek, S.; Qin, P.; Lee, Y.; Cho, K. T.; Gao, P.; Grancini, G. Dopant-Free Hole-Transporting Materials for Stable and Efficient Perovskite Solar Cells Dopant-Free Hole-Transporting Materials for Stable and Efficient Perovskite Solar Cells. Adv. Mater. 2017, 29, 1606555. 